\title{
The Effects of Producers' Expectations on Output Variations in EU-Countries
}

\author{
Tobias F. Rötheli ${ }^{1}$ \\ ${ }^{1}$ University of Erfurt, Germany \\ Correspondence: Tobias Rötheli, Department of Economics, University of Erfurt, Nordhäuser Strasse 63, 99105 \\ Erfurt, Germany. Tel: 49-361-737-4531. E-mail: tobias.roetheli@uni-erfurt.de
}

Received: January 16, 2014

Accepted: January 24, 2014

Online Published: March 25, 2014

doi:10.5539/ijef.v6n4p1

URL: http://dx.doi.org/10.5539/ijef.v6n4p1

\begin{abstract}
This paper uses survey data from the 10 largest EU countries to investigate the role of producers' expectations in the determination of aggregate output. For each country we define an output variable that captures the country's deviation in terms of economic growth from the rest of the EU. A first round of estimates documents for each country the persistence of the deviation of its output growth relative to the growth in the rest of the EU. In a second round of estimates we make use of the survey data on expected output and show that this variable explains a significant part of the observed output differences. A further round of estimates adds selling price expectations as explanatory variables to the estimation. Finally, VAR models are estimated which allow an assessment of the quantitative effects of expectation shocks on aggregate production. Overall, our results support earlier and very recent findings from other studies suggesting the importance of variations in expectations as drivers of output variations.
\end{abstract}

Keywords: producers' expectations, survey data, EU countries

\section{Introduction}

This article investigates countries' output development in comparison to their neighbors' development. Specifically, we focus on EU countries and study the deviations of national output trends from the rest of the European Union (Note 1). These deviations pose distinct policy challenges. The conduct of both monetary policy, particularly for the subset of countries belonging to the Eurozone, and fiscal policy becomes more difficult when large and lasting disparities in national output trends develop. We use survey data from the European Commission's harmonized survey program. Survey data make it possible to investigate the role expectations play regarding the course of countries' output. Expectations are particularly interesting since theorists have recently studied models of the business cycle in which bounded rationality plays a prominent role. In these studies cycles in aggregate output emanate from agents' suboptimal use of information (Jaimovich \& Rebelo, 2007; De Grauwe, 2011). Business cycle researchers of earlier years, notably Pigou (1929), considered overreactions in expectations to be an important driver of cycles. Empirical analysis using survey data and incorporating expectations effects have already been presented for individual countries (for Sweden see Hansson et al., 2005; for the U.S. see Leduc \& Sill, 2013). Besides these contributions addressing issues of business cycles there is a substantial literature using survey data to test hypotheses concerning expectations formation (see Pesaran \& Weale, 2006, for a survey). Our analysis has in common with other European studies that the survey covers producers and their expectations. Hence, when expected production is surveyed we use answers of firms' representatives regarding the projection of their own output. This is quite distinct from the surveys used in U.S. studies which rely on households' or experts' perceptions of the future course of GDP.

The article is structured as follows: section 2 describes the data. Section 3 statistically relates the survey data of production realizations to other measures of production like GDP and industrial production. Section 4 documents single equation analyses of the output data and evaluates the role of expectations. Section 5 offers results from small VAR models which allow an assessment of the role expectation shocks play regarding the course of aggregate output. Section 6 concludes this article.

\section{Data}

For the analysis that follows the production data of each country is compared to a series consisting of the 
weighted average of the other countries' production (called "rest-EU production"). EU here means the largest 10 EU economies, that is, Germany, the U.K., France, Italy, Spain, the Netherlands, Belgium, Sweden, Austria and Poland (abbreviated as GE, U.K., FR, IT, SP, NL, BE, SWE, AU and PL). The weights of the countries' variables for the computations of the rest-EU variables are based on the average size of annual GDP (measured in U.S. $\$$ as computed by the OECD) over the period from 1993 to 2010 (Note 2). The survey data regarding output report the answers of firms to the question "How has your production developed over the past 3 months?" Respondents can answer this question either with "It has increased", "It has remained unchanged", or "It has decreased". The data reported by the European Commission used in this study consists of the balances subtracting the fraction of decrease-answers from the fraction of increase-answers. All of the data are monthly observations and are seasonally not adjusted. Figure 1 shows the deviation of realized output in each country from the thus defined rest-EU output. Assessed by the Phillips-Perron test statistic these variables are (at the 1\% level of significance) judged to be stationary for all countries (Note 3). The charts show interesting features of the individual countries' performance. Take Germany as an example and notice how the German economy after years of slow growth started to outperform its EU neighbors in recent years. France and the U.K. on the contrary performed stronger than other EU countries in the middle or late 1990s while falling back afterwards. The graphical displays also indicate that for several countries the measured deviations from the rest-EU are quite persistent over time. The Netherlands and Sweden are examples for countries where the deviations of output from the EU trend are rather short-lived.

Measures of expectations which will become relevant in this study come from answers to the two questions "How do you expect your production to develop over the next 3 months?" and "How do you expect your selling prices to change over the next 3 months?" Answers here come in the form of the possible responses "It (They) will increase", "remain unchanged", or "decrease".

\section{Relation to Other Output Measures and Tests of Rationality}

In the empirical work that follows we will focus on the survey data for both expectations and the realizations of production. However, it is important to initially assess how the survey measure of output realizations compares to well-known measures of aggregate output, such as GDP and industrial production. For this purpose we select the example of Germany as the largest EU economy. The first regression based on quarterly data reported below indicates how the annual growth rate of real GDP is related to the survey responses regarding realized production changes:

$$
\begin{aligned}
{\left[\ln \left(G D P_{t}\right)-\ln \left(G D P_{t-4}\right)\right] \cdot 100=} & 1.5243+0.0475 q_{t}+0.0640 q_{t-1}+0.0418 q_{t-2}+0.0202 q_{t-3}+0.3934 u_{\mathrm{t}-1}+\varepsilon_{\mathrm{t}} \\
& \left(\begin{array}{lllll}
0.1920) & (0.0125) & (0.0179) & (0.0142) & (0.0109)
\end{array}\right.
\end{aligned}
$$

SMPL: 1992:Q3 2012:Q2, $R^{2}=0.7903, S E E=1.063, D W=2.023$.

The $q$-variables in the estimate denote the last monthly observation of survey data from the respective quarter. Thus, for explaining the change in real GDP over the previous year we have to take into account the contemporaneous production survey data (covering the most recent three months) as well as the three lagged terms of this variable. The estimate documents that roughly $80 \%$ of the variations of GDP growth can be explained with the survey data on output realizations. For the measure of the industrial production (again for Germany) we use monthly data. For this index of aggregate output the estimated relationship with the survey data of output realization is

$$
\begin{aligned}
& {\left[\ln \left(I N D_{t}\right)-\ln \left(I N D_{t-3}\right)\right] \cdot 100=0.5317+0.1218 q_{t}+0.3921 \varepsilon_{t-2}-0.4728 \varepsilon_{t-3}+\varepsilon_{t}} \\
& \begin{array}{llll}
(0.2120) & (0.0160) & (0.0520) & (0.0521)
\end{array}
\end{aligned}
$$

SMPL: 1992:M4 2012:M6, $R^{2}=0.890, S E E=3.444, D W=2.032$. 

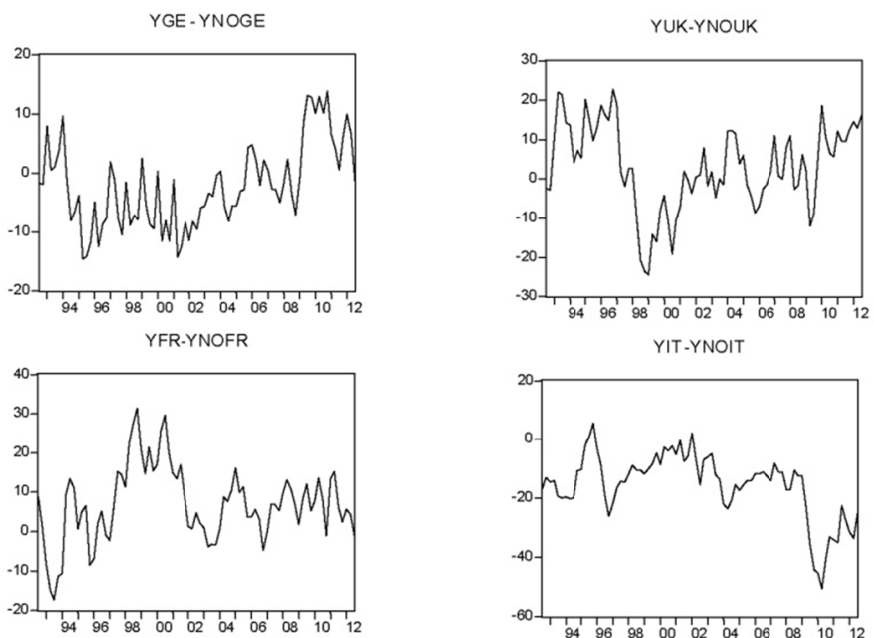

YIT-YNOIT
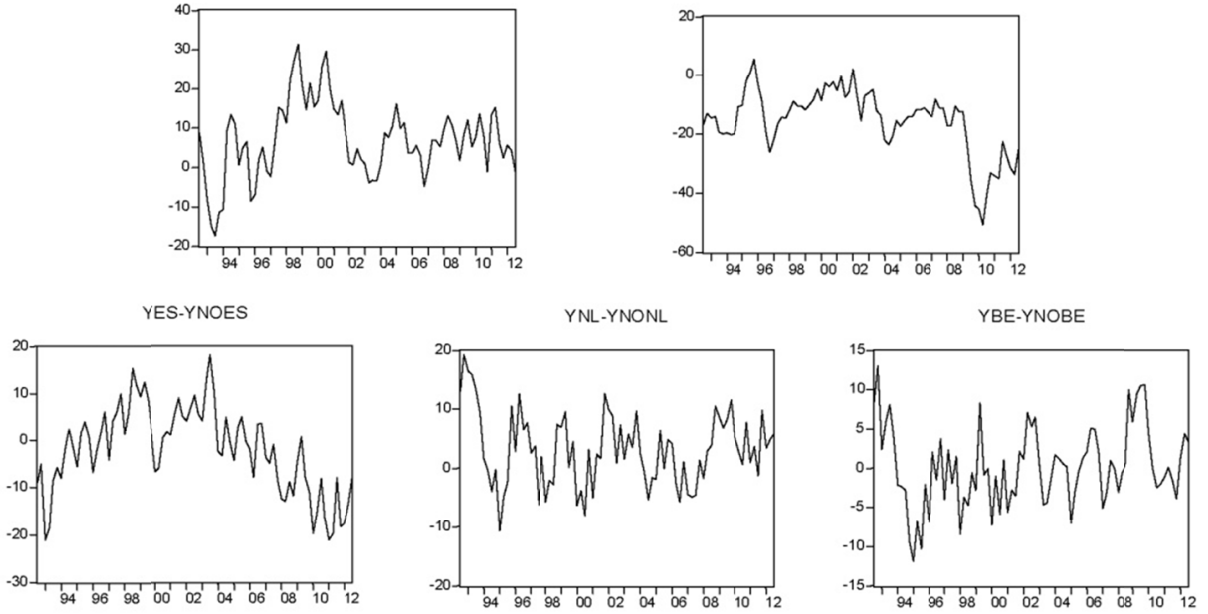

YSNE-YNOSWE

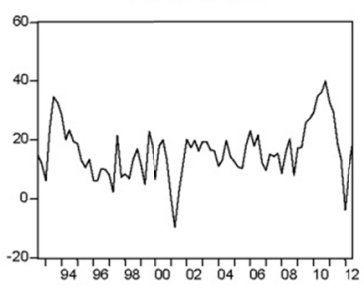

YAU-YNOAU

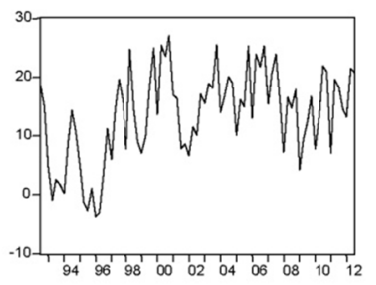

YPL-YNOPL

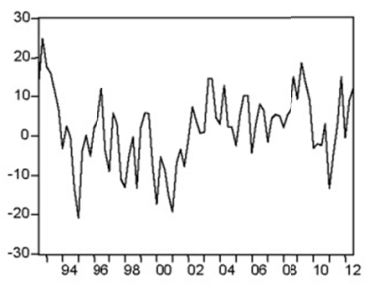

Figure 1. Country specific changes in production

Here we have as the left-hand variable the percentage change of industrial output over one quarter. Hence, only one (the concurrent) value of the survey data enters the estimate. Besides the moving average terms in (2) we also include seasonal dummies. Regressions (1) and (2) indicate that there is a close connection between the survey measure of output realizations and both the real GDP and industrial production. Given that the survey covers the manufacturing sector it is not surprising that, assessed by the $R^{2}$-value, the connection to industrial production appears stronger than the connection to GDP.

Although the primary focus of this paper is not on rationality tests, we nevertheless report results on two forms of rationality tests using the expected and realized production data. In this endeavor it is important to deal with the overlapping nature of the survey data. Since the survey spans 3 months with the sampling being monthly, a shock to actual production in any month affects the realized and reported production in three consecutive periods. This introduces a serial correlation in the errors of regression equations relating production realizations to output anticipation. This problem is dealt with here following the approach described in Hansen and Hodrick (1980) by transforming the monthly data set into 3 sets of quarterly (and non-overlapping) data. This approach does not waste any observations and allows unbiased coefficient estimates. This approach implies that the lags in the equations that follow are to be understood as quarterly lags. The first test for rationality of expectations, following Mincer and Zarnowitz (1969), estimates an equation of the form

$$
q_{i, t}=\phi_{0}+\phi_{1} q_{i, t-1}^{e}+\varepsilon_{t}
$$

And then tests the requirements imposed by rationality that (i) $\phi_{0}=0$, (ii) $\phi_{1}=1$, and (iii) that the errors should be serially uncorrelated. For 9 out of 10 countries the two joint parameter restrictions are rejected at the one percent level of significance and for the remaining country (France) the errors of the regression are significantly 
autocorrelated. Hence, these results do not support the hypothesis of rational expectations. Some authors prefer another type of rationality test which, instead of equation (3), is based on the regression equation

$$
q_{i, t}-q_{i, t-1}^{e}=\mu_{0}+\varepsilon_{t}
$$

Following this lead, rationality requires the estimated $\mu_{0}$ to be zero and the residuals to be uncorrelated. Applying this test leads to the same assessment as before: the data for all countries except for France reject the unbiasedness requirement for expectations and for the case of France the residuals (i.e., the expectations errors) are significantly autocorrelated when assessed by a Lagrange multiplier test. Overall, these results are indicative for the presence of bounded rationality in the expectations formation processes concerning production.

\section{Single Equation Analysis}

This section develops models in order to explain the output realization data from the survey. We start the estimates with a simple autoregressive specification for the country specific change of output that considers four lagged values of the endogenous variable. Specifically, the following specification is estimated:

$$
q_{i, t}-q_{i, t}^{*}=\alpha_{0}+\sum_{k=1}^{4} \alpha_{k}\left(q_{i, t-k}-q^{*}{ }_{i, t-k}\right)+\varepsilon_{t}
$$

Here, $q_{i, t}$ stands for $i$-th country's realized output change (as measured in the survey) and $q^{*}{ }_{i, t}$ stands for the rest-EU (defined relative to country $i$ ) output change. Table 1 shows the results. Standard errors of the coefficients are shown below the estimated coefficients. The estimated coefficients for the lagged endogenous variables confirm the impression from figure 1. For all countries the deviation of a country's output from that of the rest of the EU is positively and significantly autocorrelated. The Cusum of squares test indicates that the basic autoregressive specification of (5) leads to coefficient estimates that are stable for 6 countries (GE, U.K., FR, IT, NL, BE) and alerts us of parameter instability for 4 countries (SP, SWE, AU, PL).

Table 1. Results of basic estimates

\begin{tabular}{lcccccccccc}
\hline & GE & U.K. & FR & IT & SP & NL & BE & SWE & AU & PL \\
\hline$C$ & -0.326 & 0.584 & $2.322^{* *}$ & $-2.57^{* *}$ & -0.184 & $1.005^{*}$ & -0.155 & $6.744^{* *}$ & $3.523^{* *}$ & 0.204 \\
& 0.497 & 0.557 & 0.497 & 0.619 & 0.389 & 0.419 & 0.330 & 1.275 & 1.163 & 0.653 \\
$q_{t-1}-q^{*}{ }_{t-1}$ & $0.426^{* *}$ & $0.720^{* *}$ & $0.691^{* *}$ & $0.876^{* *}$ & $0.569^{* *}$ & $0.432^{* *}$ & $0.340^{* *}$ & $0.526^{* *}$ & $0.241^{* *}$ & $0.318^{* *}$ \\
& 0.064 & 0.074 & 0.061 & 0.090 & 0.065 & 0.068 & 0.062 & 0.083 & 0.090 & 0.065 \\
$q_{t-2}-q^{*}{ }_{t-2}$ & $0.172^{*}$ & -0.047 & -0.027 & -0.060 & $0.208^{*}$ & $0.328^{* *}$ & $0.287^{* *}$ & 0.137 & $0.324^{* *}$ & $0.193^{* *}$ \\
& 0.065 & 0.088 & 0.076 & 0.092 & 0.081 & 0.071 & 0.088 & 0.089 & 0.065 & 0.047 \\
$q_{t-3}-q_{t-3}^{*}$ & $-0.150^{*}$ & 0.012 & 0.121 & 0.004 & -0.025 & $-0.244^{* *}$ & -0.129 & -0.036 & -0.002 & -0.079 \\
& 0.062 & 0.093 & 0.079 & 0.110 & 0.078 & 0.085 & 0.068 & 0.080 & 0.068 & 0.064 \\
$q_{t-4}-q_{t-4}^{*}$ & $0.371^{* *}$ & 0.105 & -0.077 & 0.024 & 0.086 & 0.052 & -0.014 & -0.051 & $0.193^{* *}$ & $0.205^{* *}$ \\
& 0.067 & 0.070 & 0.054 & 0.056 & 0.065 & 0.068 & 0.075 & 0.049 & 0.070 & 0.076 \\
$R^{2}$ & 0.560 & 0.587 & 0.568 & 0.709 & 0.664 & 0.460 & 0.312 & 0.436 & 0.430 & 0.462 \\
$S S R$ & 6.221 & 7.992 & 6.845 & 6.623 & 5.644 & 5.437 & 5.000 & 8.144 & 7.010 & 8.717 \\
$D W$ & 1.848 & 2.035 & 2.055 & 1.982 & 1.945 & 1.950 & 1.999 & 2.038 & 1.933 & 1.870 \\
\hline
\end{tabular}

Note. * following a coefficient value indicates significance of the estimate at the $5 \%$ level of significance. $* *$ following a coefficient value indicates significance of the estimate at the $1 \%$ level of significance.

The next round of estimates retains the lag structure used before (i.e., a maximum lag length of 4 quarters) and introduces the expected change in output as an additional explanatory variable. Hence, here effects working via expectations are introduced. We allow for the possibility that the domestic $\left(q^{e}\right)$ and the foreign $\left(q^{* e}\right)$ expectations have non-symmetrical effects. Specifically, the following equation is estimated:

$$
q_{i, t}-q^{*}{ }_{i, t}=\alpha_{0}+\sum_{k=1}^{4} \alpha_{k}\left(q_{i, t-k}-q^{*}{ }_{i, t-k}\right)+\sum_{k=1}^{4} \beta_{k} q_{i, t-k}^{e}+\sum_{k=1}^{4} \gamma_{k} q_{i, t-k}^{* e}+\varepsilon_{t}
$$

Table 2 shows the results. In a sequential procedure Wald tests are applied to test whether the expected output variables have explanatory power and whether the domestic and the foreign variable have symmetric effects. For all of the 10 countries the first hypothesis is maintained at the $1 \%$ significance level. In cases where the second hypothesis is maintained table 2 reports the same absolute value for the coefficient on the domestic and the 
foreign variable. Hence, foreign and domestic expected output changes significantly help to explain the course of countries' output deviations from the rest of the EU. Testing for stability of the estimated coefficients the Cusum of squares test indicates that specification (6) leads to stable coefficient estimates for 6 countries (GE, U.K., FR, IT, NL, AU) and to parameter instability for 4 countries (SP, BE, SWE, PL).

Table 2. Estimates including expected output variables

\begin{tabular}{|c|c|c|c|c|c|c|c|c|c|c|}
\hline & GE & U.K. & FR & IT & SP & NL & BE & SWE & $\mathbf{A} \mathbf{U}$ & PL \\
\hline \multirow[t]{2}{*}{ C } & -0.915 & 0.071 & $2.981 * *$ & $-7.95 * *$ & -0.111 & $0.941 *$ & $3.852 * *$ & $8.154 * *$ & $3.320 * *$ & $3.513 * *$ \\
\hline & 0.521 & 0.622 & 0.643 & 1.644 & 0.564 & 0.433 & 0.961 & 1.843 & 1.093 & 1.154 \\
\hline \multirow[t]{2}{*}{$q_{t-1}-q_{t-1}^{*}$} & $0.401 * *$ & $0.497 * *$ & $0.500^{* *}$ & $0.505^{* *}$ & $0.435^{* *}$ & $0.330^{* *}$ & 0.099 & $0.311 * *$ & $0.184 *$ & 0.114 \\
\hline & 0.062 & 0.067 & 0.061 & 0.085 & 0.061 & 0.065 & 0.072 & 0.072 & 0.085 & 0.066 \\
\hline \multirow[t]{2}{*}{$q_{t-2}-q_{t-2}^{*}$} & $0.201 * *$ & 0.002 & 0.052 & 0.003 & $0.142 *$ & $0.295^{* *}$ & 0.145 & 0.091 & $0.274 * *$ & $0.220 * *$ \\
\hline & 0.058 & 0.085 & 0.075 & 0.103 & 0.072 & 0.070 & 0.080 & 0.079 & 0.062 & 0.049 \\
\hline \multirow[t]{2}{*}{$q_{t-3}-q_{t-3}^{*}$} & -0.115 & 0.116 & $0.160 *$ & 0.142 & 0.059 & -0.144 & $-0.128^{*}$ & 0.058 & $0.146^{*}$ & 0.107 \\
\hline & 0.069 & 0.083 & 0.079 & 0.083 & 0.074 & 0.082 & 0.062 & 0.068 & 0.070 & 0.072 \\
\hline \multirow[t]{2}{*}{$q_{t-4}-q_{t-4}^{*}$} & $0.379 * *$ & $0.187^{* *}$ & -0.059 & 0.099 & 0.027 & $0.154^{*}$ & 0.011 & 0.042 & 0.110 & $0.276^{* *}$ \\
\hline & 0.074 & 0.067 & 0.057 & 0.061 & 0.062 & 0.061 & 0.072 & 0.054 & 0.059 & 0.081 \\
\hline \multirow[t]{2}{*}{$q_{t-1}^{e}$} & $0.263 * *$ & $0.364 * *$ & $0.407 * *$ & $0.474 * *$ & $0.478^{* *}$ & $0.325^{* *}$ & $0.190 * *$ & $0.350 * *$ & $0.390 * *$ & $0.214 * *$ \\
\hline & 0.080 & 0.069 & 0.078 & 0.068 & 0.071 & 0.070 & 0.071 & 0.077 & 0.089 & 0.073 \\
\hline \multirow[t]{2}{*}{$q_{t-1}^{* e}$} & $-0.26^{* *}$ & -0.141 & $-0.35 * *$ & $-0.59 * *$ & $-0.45 * *$ & $-0.32 * *$ & $-0.34 * *$ & $-0.325^{*}$ & -0.067 & $-0.31 * *$ \\
\hline & 0.080 & 0.104 & 0.110 & 0.092 & 0.063 & 0.070 & 0.078 & 0.125 & 0.113 & 0.087 \\
\hline \multirow[t]{2}{*}{$q_{t-2}^{e}$} & $-0.34 * *$ & 0.004 & 0.127 & -0.015 & $0.183^{*}$ & 0.090 & -0.072 & -0.099 & 0.004 & -0.027 \\
\hline & 0.108 & 0.081 & 0.086 & 0.084 & 0.082 & 0.083 & 0.082 & 0.087 & 0.072 & 0.072 \\
\hline \multirow[t]{2}{*}{$q^{* e} e_{t-2}$} & $0.344 * *$ & -0.048 & -0.163 & $0.531^{* *}$ & -0.099 & -0.090 & 0.003 & -0.045 & -0.104 & $-0.299 *$ \\
\hline & 0.108 & 0.143 & 0.136 & 0.131 & 0.086 & 0.083 & 0.102 & 0.142 & 0.121 & 0.140 \\
\hline \multirow[t]{2}{*}{$q_{t-3}^{e}$} & 0.024 & -0.094 & $-0.20 * *$ & -0.064 & $0.108^{* *}$ & 0.069 & 0.067 & 0.023 & -0.115 & $-0.45 * *$ \\
\hline & 0.105 & 0.081 & 0.085 & 0.084 & 0.089 & 0.111 & 0.077 & 0.078 & 0.090 & 0.073 \\
\hline \multirow[t]{2}{*}{$q^{* e^{*}-3}$} & -0.024 & -0.113 & $0.417 * *$ & -0.061 & 0.161 & -0.069 & $-0.25^{* *}$ & -0.072 & 0.029 & $0.273^{*}$ \\
\hline & 0.105 & 0.178 & 0.116 & 0.172 & 0.092 & 0.111 & 0.087 & 0.159 & 0.150 & 0.132 \\
\hline \multirow[t]{2}{*}{$q_{t-4}^{e}$} & -0.061 & $-0.214^{*}$ & -0.134 & -0.162 & $-0.34 * *$ & $-0.38 * *$ & 0.000 & $-0.157^{*}$ & $-0.21 * *$ & 0.063 \\
\hline & 0.090 & 0.092 & 0.079 & 0.083 & 0.089 & 0.093 & 0.066 & 0.080 & 0.074 & 0.072 \\
\hline \multirow[t]{2}{*}{$q_{t-4}^{* e}$} & 0.061 & $0.320 * *$ & -0.142 & $0.288^{*}$ & $0.140^{*}$ & $0.389 * *$ & 0.058 & 0.001 & 0.145 & $0.398 * *$ \\
\hline & 0.090 & 0.122 & 0.097 & 0.122 & 0.068 & 0.093 & 0.084 & 0.138 & 0.117 & 0.110 \\
\hline$R^{2}$ & 0.589 & 0.677 & 0.664 & 0.828 & 0.765 & 0.551 & 0.498 & 0.573 & 0.581 & 0.632 \\
\hline$S S R$ & 6.071 & 7.205 & 6.153 & 5.191 & 4.809 & 5.006 & 4.352 & 7.223 & 6.123 & 7.347 \\
\hline$D W$ & 1.863 & 2.004 & 2.069 & 2.024 & 1.895 & 1.988 & 1.994 & 2.073 & 1.964 & 2.026 \\
\hline
\end{tabular}

Note. * following a coefficient value indicates significance of the estimate at the $5 \%$ level of significance. ** following a coefficient value indicates significance of the estimate at the $1 \%$ level of significance.

For a last set of regression estimates we add the expected change in selling prices, both at home $\left(p^{e}\right)$ and abroad $\left(p^{*}\right)$, to the list of explanatory variables. The new equation to be estimated is

$$
q_{i, t}-q_{i, t}^{*}=\alpha_{0}+\sum_{k=1}^{4} \alpha_{k}\left(q_{i, t-k}-q_{i, t-k}^{*}\right)+\sum_{k=1}^{4} \beta_{k} q_{i, t-k}^{e}+\sum_{k=1}^{4} \gamma_{k} q_{i, t-k}^{* e}+\sum_{k=1}^{4} \phi_{k} p_{i, t-k}^{e}+\sum_{k=1}^{4} \vartheta_{k} p_{i, t-k}^{*}+\varepsilon_{t}
$$

As before Wald tests are applied to test whether (i) the expectations variables have explanatory power and, (ii) whether domestic and foreign variables have symmetric effects. Table 3 shows the estimated regressions resulting from this specification process. In 8 out of 10 countries (with Belgium and Austria being the exceptions) adding expected changes in selling prices - domestic and foreign - adds significantly to the explanatory power of the estimate. The effects of the expected change in prices are either positive or negative, depending on which country we look at. In some countries the demand effect dominates with higher expected prices signaling higher profit opportunities. In other countries higher expected prices appear to signal higher costs and thus tend to reduce output. With the most encompassing specification of (7) the Cusum of squares test indicates that the coefficient estimates are stable for all but one country (SWE). Still, the estimate for Sweden passes the less 
demanding Cusum test (Note 4).

Table 3. Estimates including expected output and expected price variables

\begin{tabular}{|c|c|c|c|c|c|c|c|c|c|c|}
\hline & GE & U.K. & FR & IT & SP & NL & $\mathbf{B E}$ & SWE & $\mathbf{A U}$ & PL \\
\hline \multirow[t]{2}{*}{$C$} & $2.485^{* *}$ & -0.057 & $2.562 * *$ & $-7.32 * *$ & -0.672 & 1.083 & $3.852 * *$ & $11.612 * *$ & $3.320 * *$ & $3.234 * *$ \\
\hline & 1.056 & 0.677 & 0.704 & 1.671 & 0.559 & 0.800 & 0.961 & 2.005 & 1.093 & 1.292 \\
\hline \multirow[t]{2}{*}{$q_{t-1}-q_{t-1}^{*}$} & $0.280 * *$ & $0.440 * *$ & $0.439^{* *}$ & $0.411 * *$ & $0.411 * *$ & $0.238^{* *}$ & 0.099 & $0.213^{*}$ & $0.184^{*}$ & 0.094 \\
\hline & 0.066 & 0.076 & 0.060 & 0.092 & 0.059 & 0.059 & 0.072 & 0.072 & 0.085 & 0.071 \\
\hline \multirow[t]{2}{*}{$q_{t-2}-q_{t-2}^{*}$} & $0.147 * *$ & -0.025 & 0.056 & 0.029 & $0.149 *$ & $0.296^{* *}$ & 0.145 & 0.064 & $0.274 * *$ & $0.220^{* *}$ \\
\hline & 0.051 & 0.078 & 0.072 & 0.095 & 0.070 & 0.074 & 0.080 & 0.076 & 0.062 & 0.043 \\
\hline \multirow[t]{2}{*}{$q_{t-3}-q_{t-3}^{*}$} & -0.086 & 0.098 & $0.178^{*}$ & $0.174 *$ & 0.072 & -0.086 & $-0.128^{*}$ & 0.099 & $0.146^{*}$ & 0.107 \\
\hline & 0.068 & 0.080 & 0.073 & 0.081 & 0.073 & 0.088 & 0.062 & 0.069 & 0.070 & 0.070 \\
\hline \multirow{2}{*}{$q_{t-4}-q_{t-4}^{*}$} & $0.452 * *$ & $0.209 * *$ & -0.064 & 0.111 & 0.024 & $0.198^{* *}$ & 0.011 & -0.001 & 0.110 & $0.294 * *$ \\
\hline & 0.063 & 0.067 & 0.058 & 0.063 & 0.062 & 0.059 & 0.072 & 0.058 & 0.059 & 0.080 \\
\hline \multirow[t]{2}{*}{$q_{t-1}^{e}$} & $0.331 * *$ & $0.251 * *$ & $0.378^{* *}$ & $0.257^{* *}$ & $0.451^{* *}$ & $0.225^{* *}$ & $0.190^{* *}$ & $0.330^{* *}$ & $0.390^{* *}$ & $0.187^{*}$ \\
\hline & 0.084 & 0.070 & 0.076 & 0.082 & 0.073 & 0.069 & 0.071 & 0.073 & 0.089 & 0.073 \\
\hline \multirow[t]{2}{*}{$q^{*_{e}}{ }_{t-1}$} & $-0.33^{* *}$ & -0.006 & $-0.35^{* *}$ & $-0.51 * *$ & $-0.46 * *$ & $-0.22 * *$ & $-0.34 * *$ & $-0.55^{* *}$ & -0.067 & -0.034 \\
\hline & 0.084 & 0.140 & 0.103 & 0.092 & 0.066 & 0.069 & 0.078 & 0.163 & 0.113 & 0.114 \\
\hline \multirow[t]{2}{*}{$q_{t-2}^{e}$} & -0.103 & 0.017 & 0.143 & -0.136 & $0.182 *$ & 0.046 & -0.072 & -0.061 & 0.004 & -0.022 \\
\hline & 0.109 & 0.075 & 0.078 & 0.084 & 0.082 & 0.084 & 0.082 & 0.093 & 0.072 & 0.079 \\
\hline \multirow{2}{*}{$q^{*} e_{t-2}$} & 0.103 & -0.216 & -0.194 & $0.400^{* *}$ & -0.102 & -0.046 & 0.003 & -0.185 & -0.104 & $-0.46^{* *}$ \\
\hline & 0.109 & 0.158 & 0.119 & 0.138 & 0.087 & 0.084 & 0.102 & 0.175 & 0.121 & 0.147 \\
\hline \multirow[t]{2}{*}{$q_{t-3}^{e}$} & 0.096 & -0.096 & $-0.18^{* *}$ & -0.102 & 0.109 & 0.057 & 0.067 & 0.001 & -0.115 & $-0.37 * *$ \\
\hline & 0.116 & 0.085 & 0.086 & 0.081 & 0.088 & 0.098 & 0.077 & 0.083 & 0.090 & 0.070 \\
\hline \multirow[t]{2}{*}{$q_{t-3}^{* e}$} & -0.096 & -0.169 & $0.376^{* *}$ & 0.077 & 0.160 & -0.057 & $-0.25^{* *}$ & -0.063 & 0.029 & 0.250 \\
\hline & 0.116 & 0.177 & 0.116 & 0.155 & 0.089 & 0.098 & 0.087 & 0.172 & 0.150 & 0.140 \\
\hline \multirow[t]{2}{*}{$q_{t-4}^{e}$} & -0.098 & -0.172 & $-0.171^{*}$ & $-0.157^{*}$ & $-0.33 * *$ & $-0.36^{* *}$ & 0.000 & -0.151 & $-0.21 * *$ & 0.139 \\
\hline & 0.091 & 0.097 & 0.076 & 0.079 & 0.085 & 0.071 & 0.066 & 0.082 & 0.074 & 0.071 \\
\hline \multirow[t]{2}{*}{$q^{* e} e_{t-4}$} & 0.098 & 0.207 & -0.118 & $0.424 * *$ & $0.171^{* *}$ & $0.362^{* *}$ & 0.058 & 0.112 & 0.145 & $0.299 *$ \\
\hline & 0.091 & 0.129 & 0.087 & 0.120 & 0.066 & 0.071 & 0.084 & 0.156 & 0.117 & 0.123 \\
\hline \multirow[t]{2}{*}{$p_{t-1}^{e}$} & -0.202 & $0.219^{*}$ & 0.077 & $0.362 * *$ & 0.029 & -0.173 & & 0.008 & & -0.039 \\
\hline & 0.163 & 0.098 & 0.075 & 0.131 & 0.054 & 0.106 & & 0.083 & & 0.081 \\
\hline \multirow[t]{2}{*}{$p^{*_{e}}{ }_{t-1}$} & -0.152 & -0.002 & -0.077 & $-0.256^{*}$ & -0.029 & -0.012 & & $0.547^{*}$ & & $-0.475 *$ \\
\hline & 0.128 & 0.167 & 0.075 & 0.116 & 0.054 & 0.100 & & 0.213 & & 0.179 \\
\hline \multirow[t]{2}{*}{$p_{t-2}^{e}$} & $-0.365^{*}$ & -0.051 & -0.076 & $0.258^{*}$ & 0.075 & -0.168 & & -0.103 & & 0.132 \\
\hline & 0.173 & 0.081 & 0.077 & 0.113 & 0.067 & 0.117 & & 0.089 & & 0.090 \\
\hline \multirow[t]{2}{*}{$p_{t-2}^{*_{e}}$} & 0.226 & 0.118 & 0.076 & 0.068 & -0.075 & $0.219^{*}$ & & -0.100 & & $0.491 *$ \\
\hline & 0.143 & 0.185 & 0.077 & 0.131 & 0.067 & 0.107 & & 0.221 & & 0.179 \\
\hline \multirow[t]{2}{*}{$p_{t-3}^{e}$} & $0.277^{*}$ & 0.074 & -0.083 & -0.155 & 0.071 & -0.035 & & -0.093 & & -0.085 \\
\hline & 0.141 & 0.089 & 0.078 & 0.121 & 0.053 & 0.097 & & 0.083 & & 0.098 \\
\hline \multirow[t]{2}{*}{$p_{t-3}^{*_{e}}$} & -0.227 & -0.068 & 0.083 & -0.117 & -0.071 & -0.114 & & 0.007 & & -0.027 \\
\hline & 0.182 & 0.142 & 0.078 & 0.133 & 0.053 & 0.111 & & 0.218 & & 0.186 \\
\hline \multirow[t]{2}{*}{$p_{t-4}^{e}$} & -0.013 & $-0.24 * *$ & $-0.20 * *$ & 0.070 & -0.008 & $0.321^{* *}$ & & 0.192 & & $-0.198 *$ \\
\hline & 0.134 & 0.080 & 0.080 & 0.092 & 0.061 & 0.085 & & 0.104 & & 0.085 \\
\hline \multirow[t]{2}{*}{$p^{*_{e}}{ }_{t-4}$} & 0.120 & $0.328 * *$ & $0.209^{* *}$ & $-0.184 *$ & 0.008 & -0.050 & & $-0.421 *$ & & 0.140 \\
\hline & 0.145 & 0.131 & 0.080 & 0.087 & 0.061 & 0.080 & & 0.182 & & 0.142 \\
\hline$R^{2}$ & 0.683 & 0.721 & 0.696 & 0.857 & 0.772 & 0.625 & 0.498 & 0.613 & 0.581 & 0.676 \\
\hline$S S R$ & 5.433 & 6.832 & 5.908 & 4.822 & 4.779 & 4.663 & 4.352 & 7.014 & 6.123 & 7.035 \\
\hline$D W$ & 1.930 & 2.069 & 2.079 & 2.079 & 1.888 & 2.067 & 1.994 & 2.024 & 1.964 & 1.994 \\
\hline
\end{tabular}

Note. * following a coefficient value indicates significance of the estimate at the $5 \%$ level of significance. ** following a coefficient value indicates significance of the estimate at the $1 \%$ level of significance.

\section{VAR Estimates}

The estimates so far do not allow an assessment of the relative importance of expectations as a propagator of 
shocks and as a separate source of shocks. The significant coefficients of expectations terms in the regressions reported in tables 2 and 3 capture two different sorts of effects. First, there is the mechanism where unexpected changes in production (e.g., induced by an unanticipated changes in technology) influence expectations which in turn affect production over the subsequent periods. Second, shocks may emanate from the side of expectations (e.g., animal spirits) and have an influence on output. We quantify this second mechanism by estimating vector autoregressive models which contain both realizations and expectations data. More specifically, for each country we estimate a small VAR model containing the three variables $q-q^{*}, p^{e}-p^{* e}$, and $q^{e}-q^{*^{e}}$. Thus, for the purpose of parsimonious representations we restrict domestic and foreign variables to have symmetrical effects. The lag length used in the VARs is determined for each country applying the Schwarz information criterion. We employ a Cholesky decomposition of the residuals for the computation of the impulse response functions with the following ordering of variables: $q-q^{*}, p^{e}-p^{* e}, q^{e}-q^{* e}$. With this choice we attribute the effects of common shocks to the variable that comes earlier in the ordering. Hence, the estimates of the impulse responses presume innovations to emanate in production first and then feeding into expectations. Hence, the effects found here concerning the importance of expectations shocks should be understood as lower bound estimates of these effects. Figure 2 documents these impulse responses for the 10 countries of this study.

The first column shows the reaction of a country's output deviation to a shock in this variable. Confirming the earlier regression results, the new estimates indicate that the half time for such shocks lies typically above two quarters. Hence, countries tend to deviate from the collective average for an extended time span. With respect to innovations in expectations two results are noteworthy. First, as already noted in the previous section, innovations in price expectations do indeed have ambiguous effects. For some countries the effects are positive and for some they are negative. Statistically significant effects, of a positive tendency, are found for the U.K. and for Italy. Negative effects are typically insignificant. Finally, we turn to the effects of shocks to production expectations. Here, we find for most countries sizable effects lasting for several periods. This last result is no proof of bounded rationality or inefficiency. Our results can be rationalized on the background of both rational and of boundedly rational agents. In the first interpretation the shocks to expectations represent optimal adjustments of expectations to news which in turn lead to efficient responses in actual production. In the second interpretations shocks to expectations are seen as fads and animal spirits or, more technically, as resulting from suboptimal inferences. For readers leaning toward an interpretation of the results as indicating bounded rationality there is one further interesting effect. Since expectations play a role in the transmission of production shocks the effects found here (i.e., the first column displays in Figure 2 can be the result of an expectations-overreaction. If producers overreact, i.e., becoming over-optimistic after production increases and over-pessimistic after production declines, the subsequent course of output may also turn out to be an overreaction (Note 5).

It might be tempting to attribute the different findings with respect to the strength of output expectation shocks in different countries to cultural differences or national mentalities. Looking at the impulse responses of Figure 2 the small and short-lasting effect for Germany could be interpreted as the outcome of German soberness and the stronger and longer-lasting effect for France as the result of a more excitable national character. Besides the obvious dubiousness of such categorizations there are two types of evidence which call for caution here: First, the strongest effect of expectations' shocks is found for the U.K., hardly a country known for moodiness or excitability. Second, experimental evidence indicates that differences in expectations formation originating from cultural differences tend to be negligible (Rötheli, 2011). Against this background, differences between national effects in production expectations are more likely to be related to what determines-and what resolves-the uncertainty of producers in a country (Note 6). In such an explanation bounded rationality can again play an important role: countries may differ with respect to the frequency and importance of new information relevant for producers. However, the impact on output of new information depends on how expectations are influenced by the arrival of new information with both underreaction and overreaction as possible responses. 
Response of $q-q^{*}$

to $q-q^{*}$

GE:
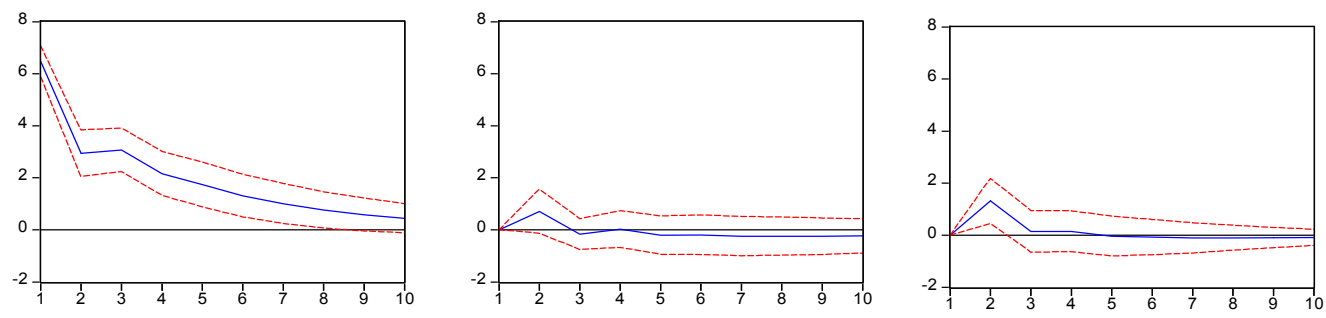

U.K.:
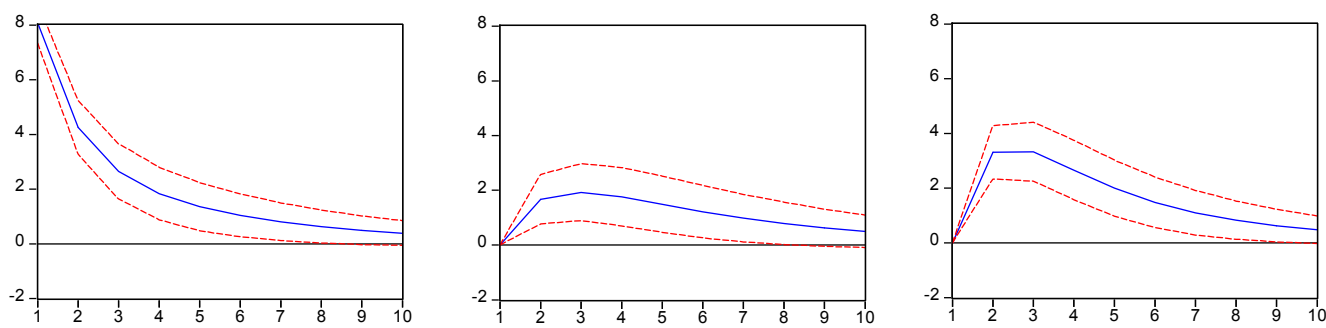

FR:
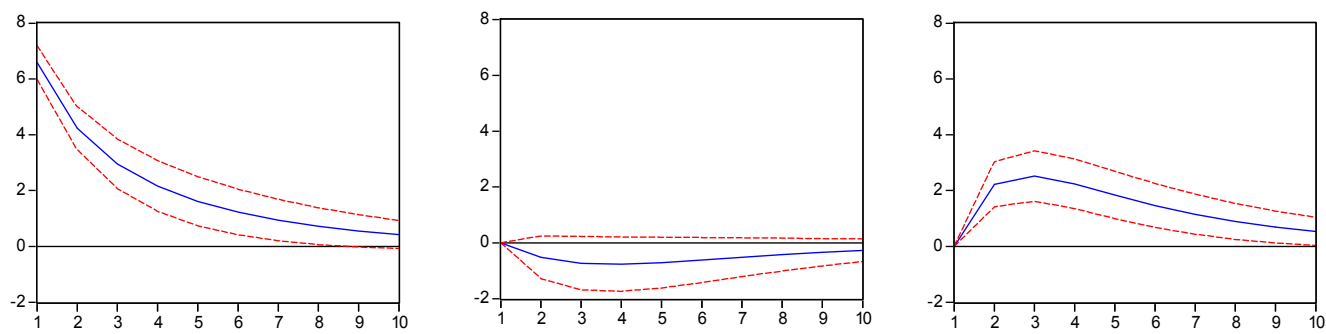

IT:
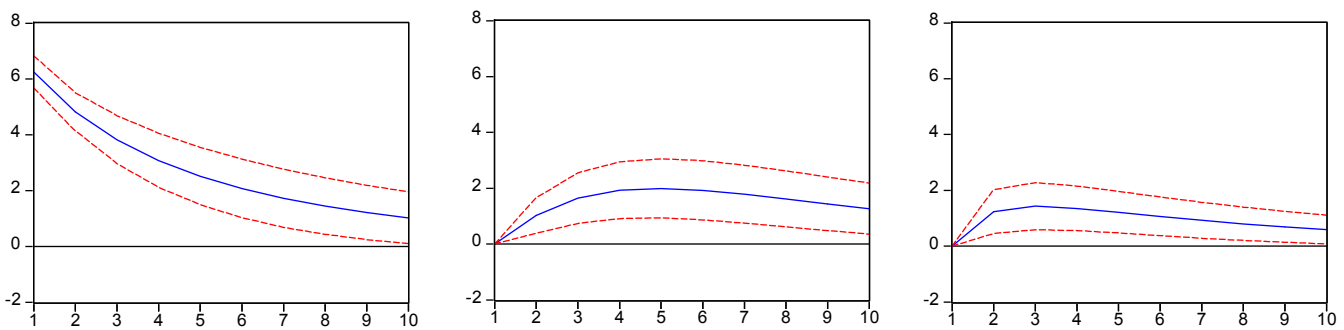

SP:
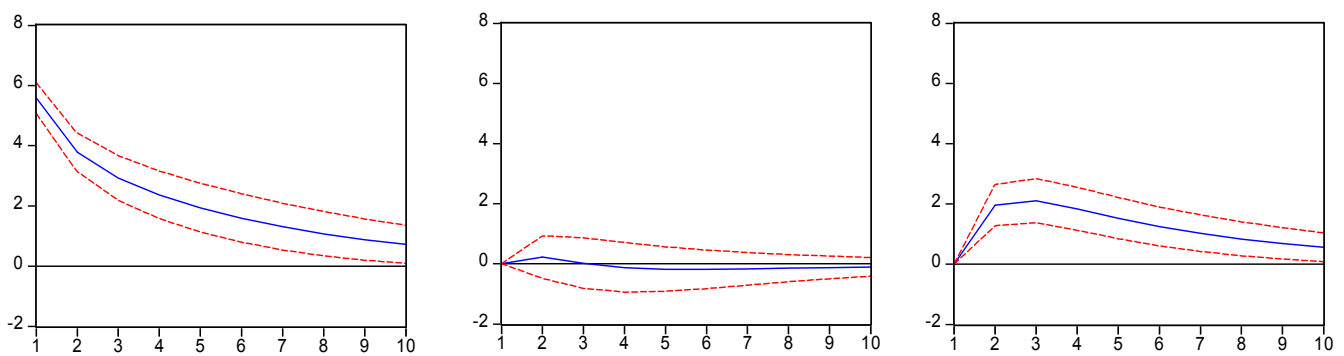

NL: 

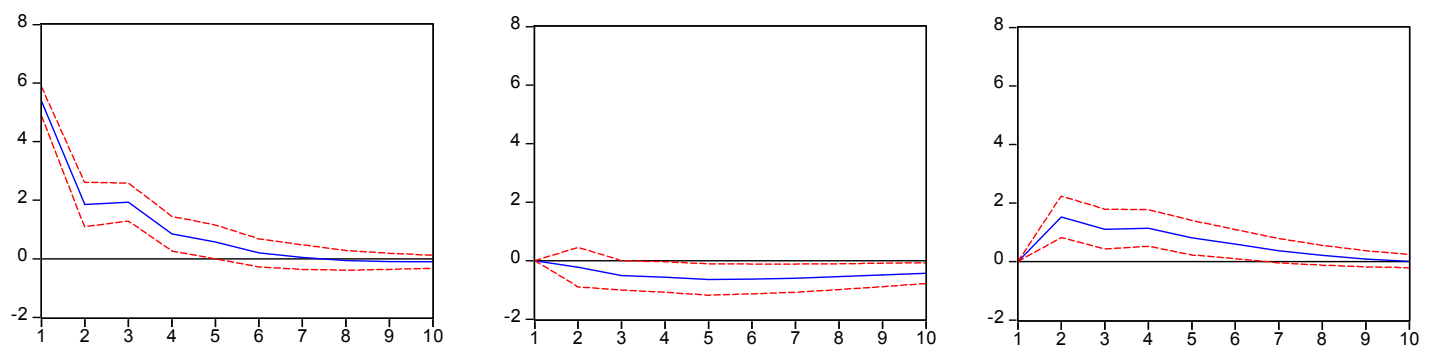

BE:
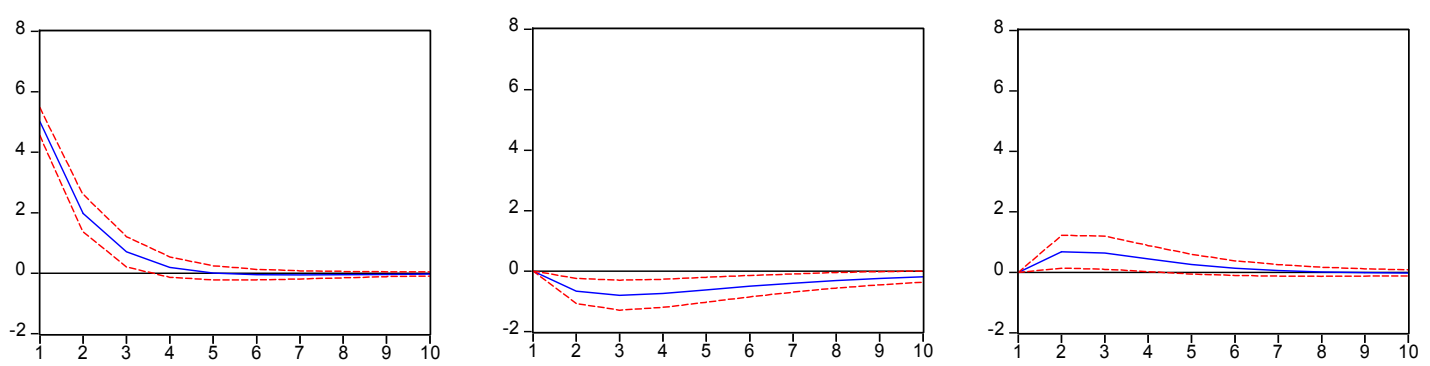

SWE:
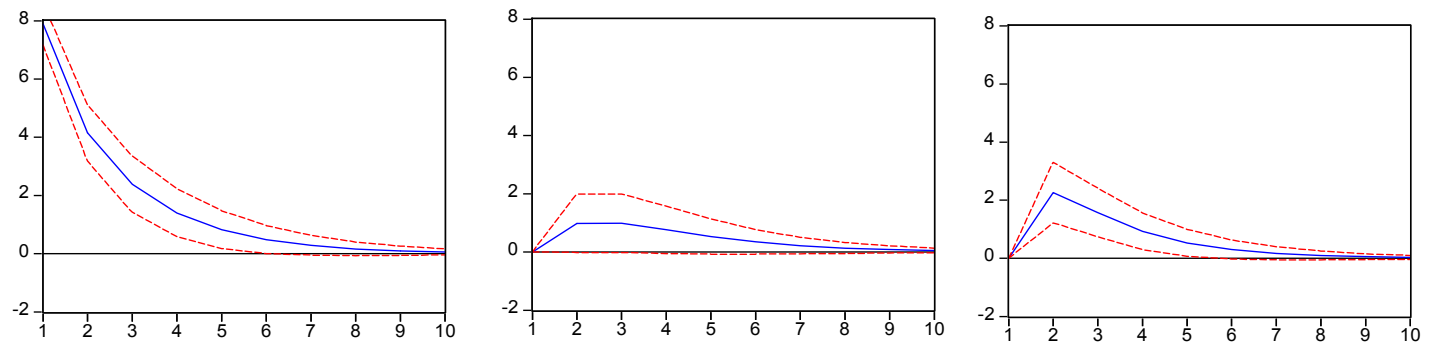

AU:
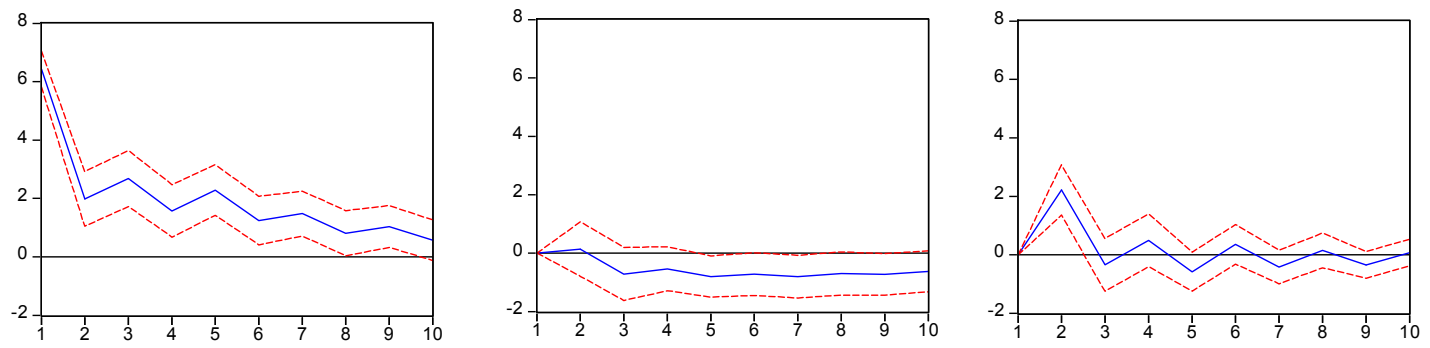

PL:
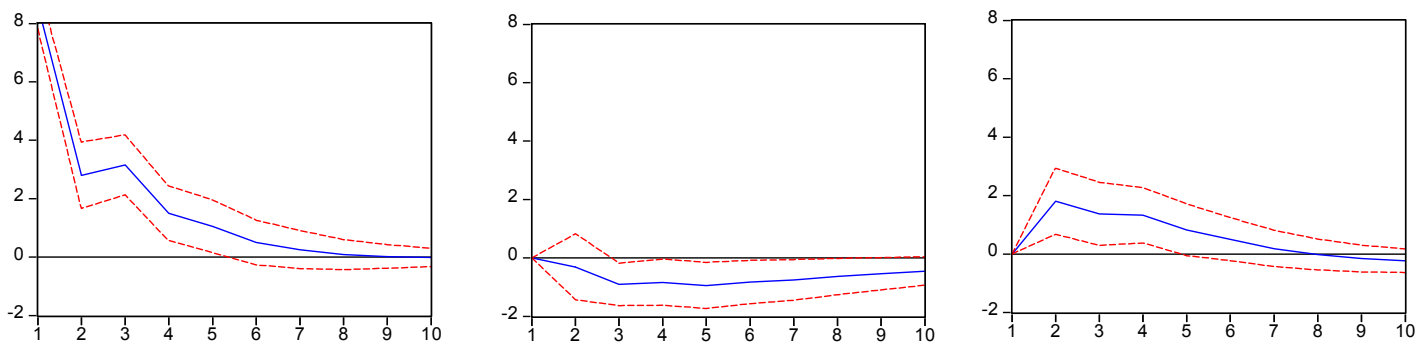

Figure 2. Impulse response of $q-q^{*}$ to various shocks for all countries 


\section{Conclusions}

This study analyzes the deviations of European countries' production growth relative to the rest of the EU using survey data from manufacturing firms. We find that these output deviations are quite persistent and influenced by expectations. Specifically, producers' output expectations are important both as a transmitter of economic shocks and as a source of shocks. Furthermore, including expectation variables tends to lead to more stable parameter estimates. The estimates presented here suggest that variations in expectations on average over all countries can account for $32 \%$ of output variation. These results are in line with the findings by Leduc and Sill (2013) pointing toward the importance of variations in expectations as a driver of U.S. output. Our estimates also support the conclusions from the simulation analysis of Jaimovich and Rebelo (2007) which suggests that expectation shocks tend to increase business cycle volatility. Estimates of VARs and their implied impulse responses show that expectations shocks concerning production have stronger and more clear-cut effects than expectations of selling price changes.

Our findings are relevant for policy makers and analysts particularly in Europe. Large and persistent deviations in growth rates of output across countries pose challenges in the coordination of monetary and fiscal policy making. These challenges are not limited (but probably more accentuated) to the countries who share the Euro as their common currency. Based on the analysis presented here it is important to note that a significant part of such tensions-e.g., same countries calling for a more expansionary and some for a more restrictive stance of monetary and fiscal policy-is due to differences in the course of expectations across countries. This clearly suggests that researching the drivers of expectations should remain a high research priority but it also reminds us of the limited controllability of economic activity.

\section{Acknowledgements}

I would like to thank Hugh Schwarz and the editor of this journal for comments.

\section{References}

De Grauwe, P. (2011). Animal spirits and monetary policy. Economic Theory, 47(2-3), 423-457. http://dx.doi.org/10.1007/s00199-010-0543-0

Hansen, L. P., \& Hodrick, R. J. (1980). Forward exchange rates as optimal predictors of future spot rates: An econometric analysis. Journal of Political Economy, 88(5), 829-853. http://dx.doi.org/10.1086/260910

Hansson, J., Jansson, P., \& Löf, M. (2005). Business survey data: Do they help in forecasting GDP growth? International Journal of Forecasting, 21(2), 377-389. http://dx.doi.org/10.1016/j.ijforecast.2004.11.003

Jaimovich, N., \& Rebelo, S. (2007). Behavioral theories of the business cycle. Journal of the European Economic Association, 5(2-3), 361-368. http://dx.doi.org/10.1162/jeea.2007.5.2-3.361

Leduc, S., \& Sill, K. (2013). Expectations and economic fluctuations: An analysis using survey data. Review of Economics and Statistics, 95(4), 1352-1367. Retrieved from http://dx.doi.org/10.1162/REST_a_00374

Mincer, J. A., \& Zarnowitz, V. (1969). The evaluation of economic forecasts. In J. Mincer (Ed.), Economic forecasts and expectations. New York: National Bureau of Economic Research.

Mumtaz, H., \& Surico, P. (2009). The transmission of international shocks: A factor-augmented VAR approach. Journal of Money, Credit, and Banking, 41(0), 71-100. http://dx.doi.org/10.1111/j.1538-4616.2008.00199.x

Pesaran, M. H., \& Weale, M. (2006). Survey expectations. In G. Elliot, C. W. J. Granger, \& A. Timmermann (Eds.), Handbook of economic forecasting (Vol. 1, Chapter 14). Elsevier, Amsterdam. http://dx.doi.org/10.1016/S1574-0706(05)01014-1

Pigou, A. C. (1929). Industrial fluctuations. London: Macmillan.

Rötheli, T. F. (2000). Producers' expectations: Their role in the monetary transmission mechanism. Kyklos, 53(1), 39-50. http://dx.doi.org/10.1111/1467-6435.00108

Rötheli, T. F. (2011). Pattern-based expectations: International experimental evidence and applications in financial economics. Review of Economics and Statistics, 93(4), 1319-1330. http://dx.doi.org/10.1162/REST_a_00125

\section{Notes}

Note 1. With this orientation we have chosen a different focus from the literature dealing with the transmission of international shocks (see, e.g., Mumatz \& Surico, 2009). 
Note 2. The relative size of the 10 economies (and the corresponding weights) according to this criterion is GE 0.2495, U.K. 0.1808, FR 0.1788, IT 0.1461, SP 0.0834, NL 0.0512, BE 0.0315, SWE 0.0305, AU 0.0259, PL 0.0224 .

Note 3. Italy is the only exception here. For this country the statistic indicates stationarity only at the $10 \%$ level of significance. Figure 1 indicates that with the onset of the recession in 2009 we see the appearance of a downward trend for Italy. If the sample is limited to the period of 1993 to 2007 the Phillips-Perron statistic indicates a rejection of the hypothesis of non-stationarity at the $1 \%$ significance level. To account for this finding all estimates for Italy that follow are subjected to Chow forecast tests and none of them indicates parameter instability over the break point of 2007:4.

Note 4. Signs of parameter instability in estimates using survey for Sweden data have also been reported by Hansson et al. (2005).

Note 5. This effect is akin to the role of expectations in the transmission of monetary shocks discussed in Rötheli (2000).

Note 6. Here, the exchange rate regime may play a role. Three countries, the U.K., Sweden and Poland do not belong to the Eurozone. When looking at the standard deviation of the trade weighted effective exchange rates of the 10 countries considered here as reported by the OECD we find for the period 1998 until 2012 the highest value for the U.K. (9.11) which would fit the explanation. However, doubts about this hypothesis arise when comparing the ranking of standard deviations for Germany (4.37), Italy (3.98), France (3.74), and Spain (3.47) with the results of figure 2 .

Note 7. Survey data come from the European Commission's harmonized survey programme: http://ec.europa.eu/economy_finance/db_indicators/surveys/time_series/index_en.htm\#data_dl

Data for weights of the 10 economies come from the OECD: http://stats.oecd.org/

Data for the German real GDP and industrial production come from the German Bundesbank: http://www.bundesbank.de/Navigation/DE/Statistiken/Zeitreihen_Datenbanken/Makrooekonomische_Zeitreihen/ makrooekonomische_zeitreihen_node.html

\section{Copyrights}

Copyright for this article is retained by the author(s), with first publication rights granted to the journal.

This is an open-access article distributed under the terms and conditions of the Creative Commons Attribution license (http://creativecommons.org/licenses/by/3.0/). 